\title{
GADAMER, ¿PENSADOR ATRIBULADO O ESTETA APOLÍTICO?
}

\author{
Asunción Herrera Guevara \\ Universidad de Oviedo
}

\begin{abstract}
RESUMEN. Este trabajo constituye un primer desarrollo de diversas intuiciones en relación al pensamiento de HansGeorg Gadamer. Uno de los retos más importantes con los que se enfrenta la actual filosofia hermenéutica es el de caracterizar adecuadamente las consecuencias ético-políticas que se derivan del pensamiento gadameriano. Propongo considerar las obras del pensador alemán como una muestra del pensamiento atribulado. Tal propuesta no exige asumir una interpretación conservadora de Gadamer.
\end{abstract}

\section{El pensamiento atribulado y sus figuras}

Cuando Kierkegaard en sus papeles de 1853 confiesa que hay hombres cuyo destino es ser sacrificados por otros, a fin de hacer progresar a la idea, está reforzando la presencia de un tipo de pensamiento dentro de la filosofía occidental: el pensamiento atribulado, apesadumbrado, o como al danés le gustaba decir, melancólico. La melancolía es uno de los sentimientos más influyentes en la obra del llamado «Sócrates del Norte». Kierkegaard denunció con suficiente vehemencia los jirones de un mundo, el mundo histórico-social que le tocó vivir, como para que entendamos por qué redunda, una y otra vez, en la imposibilidad de enamorarse de ese mundo. El sentimiento de melancolía tiene, como componente cognitivo, el reconocimiento de un entramado histórico-social hecho trizas; como componente afectivo, la tristeza, la pesadumbre por tal reconocimiento y, por último, como componente conativo, la tendencia a trastocar ese mundo de grietas y fisuras. Un espíritu melancólico está destinado a sufrir ${ }^{1}$ : cuan-

1 Véase S. KierkegaArd, Diario intimo, Buenos Aires, Santiago Rueda Ed., 1955, p. 248. 
do uno se siente íntimamente desdichado se encierra cada vez más dentro de sí, hasta que el sentimiento de melancolía se apodera totalmente de uno.

La pesadumbre por el reconocimiento de un mundo enajenado conduce a un melancólico como Kierkegaard a vagabundear por mundos de fantasía. De este modo explica el danés su necesidad vital de alejarse de sí mismo y de recorrer un entramado poético ${ }^{2}$. Necesidad imaginativa que se plasma en el uso de la comunicación indirecta y de una de sus formas, la ironía.

Karl Jaspers habla de tres tipos de filósofos: los «maestros de determinados principios" quienes se dedican a dar normas de conductas universales para que sean seguidas; los «maestros de la totalidad de la vida", los grandes constructores de sistemas que maquinan grandes habitáculos donde todo ocupa su lugar; y, por último, los "profetas de la comunicación indirecta» que se dedican a estimular, a llamar la atención, a crear un estado de intranquilidad, a hacer las cosas problemáticas y que, sin embargo, no ofrecen nada positivo. Kierkegaard, junto a otros pensadores atribulados, engrosará las filas de los profetas de la comunicación indirecta. La mayor parte de ellos, por no decir su totalidad, sintieron una desazón hacia la época que les tocó vivir. Sócrates es el primer eslabón de una cadena que llega hasta autores del siglo XX. Kierkegaard, al igual que Sócrates, pensó que toda la vida sustancial de su época había perdido validez; ahora bien, a través de la ironía simuló dejar en pie lo establecido con el fin de llevarlo a su ruina. «Para Kierkegaard no es posible ninguna amistad con el mundo, puesto que esa amistad, al asentir con el mundo tal como es, lleva a eternizar el mal e impide que llegue a ser lo que debiera ser amadon". Su contundente crítica a los acontecimientos políticos de 1848 y a las concepciones democráticas del momento le hicieron merecedor de varias etiquetas relacionadas entre sí: estaríamos ante un pensador políticamente conservador, un mandarín de la cultura, en definitiva, ante un esteta apolítico que, como dijo Jaspers de los profetas de la comunicación indirecta, no ofrecería nada positivo. Calificar de esta manera el pensamiento del danés es no haber comprendido ni el verdadero sig-

2 "Así como aquél que no posee un hogar feliz, vagabundea todo lo posible y de buena gana prescindiría de su casa, así mi melancolía me ha alejado de mí mismo, en tanto que yo con mi vida y mis hallazgos poéticos, recorría un mundo de fantasían, ibid., p. 184.

3 T. ADORNO, Kierkegaard, Caracas, Monte Ávila, p. 281. 
nificado, ni la complejidad de sus obras seudónimas, ni el de las firmadas por él ${ }^{4}$. Me explico.

En primer lugar no es un conservador a la manera tradicional del conservadurismo político de finales del XVIII y comienzos del XIX, ejemplificado en las obras de Edmund Burke o José de Maistre. De Maistre, que admiraba el pensamiento reaccionario y católico de Bonald, llevó hasta lo siniestro el pensamiento tradicionalista ${ }^{5}$. José de Maistre "en lugar de los ideales de progreso, libertad y perfectibilidad humana, predicó la salvación por medio de la tradición y de la fe. Insistió en la naturaleza incurablemente malvada y corrupta del hombre, y en la necesidad inevitable, por ello, de autoridad, jerarquía, obediencia y sometimiento. En lugar de la ciencia predicó la supremacía del instinto, de la sabiduría cristiana, del prejuicion". El conservadurismo de Kierkegaard es de otro jaez. No rechaza las verdades de la ciencia en su espacio propio, el de las verdades objetivas; pero eso sí, intenta que no ocupen el terreno de las verdades subjetivas. No encuentra la salvación de la humanidad en el terror y la autoridad, sino en el mandato "tú debes amar al prójimo" ${ }^{7}$; desea un mundo tal y como debiera ser amado en donde no tiene cabida el totalitarismo del que habla De Maistre, sino la igualdad cristiana y el amor. La democracia que critica va unida a la tiranía de la mayoría, a una concepción populista que desprecia la individualidad.

Sobre la segunda acusación - la de ser un mandarín o un ser efectista, como lo calificaron otros- sólo expondré un argumento para recusarla: Las obras del amor. La concepción de hombre que mantiene en esta obra niega cualquier imagen elitista que uno se pudiera hacer de Kierkegaard.

Por último, quisiera mantener que Kierkegaard no es un esteta apolítico, un profeta de la comunicación indirecta que no propone nada positivo. El Sócrates del Norte, o el segundo Lutero, como es llamado por otros, sí hace una propuesta.

4 Me refiero a los Discursos edificantes, Las obras del amor y Diario intimo, esta última publicada póstumamente.

5 Véase al respecto el estudio de I. Berlin en El fuste torcido de la humanidad, Barcelona, Península, 1992, pp. 103-166. Berlin encuentra en el pensamiento de De Maistre los orígenes del fascismo.

${ }^{6}$ I. BERLIN, El fuste torcido de la humanidad, op. cit., p. 117.

7 Véase S. KIERKEGAARD, Las obras del amor en Obras y papeles, Madrid, Guadarrama, 19611975,11 vols. 
Ahora bien, a diferencia de pensadores sistemáticos, como Hegel, es preciso entresacarla de la feroz crítica a su mundo desgarrado. La mayor parte de sus obras seudónimas nos anuncian cuál podría ser la imagen invertida de ese mundo. Más aún, uno de los seudónimos que utiliza, Anti-Climacus, el cristiano extraordinario, nos pone el ideal excesivamente alto. Si esto nos parece insuficiente, volvamos a Las obras del amor. En esta obra se expone una forma de vida buena, una eticidad. ¿Para no ser acusado de esteta apolítico esto no es suficiente, es preciso dar principios formales y abstractos sobre la justicia y el deber?... Unos principios de tales características no los encontraremos en el pensador danés, ni en otros muchos pensadores de la historia de la filosofía que también fueron acusados de estetas apolíticos. Adorno, en pleno siglo XX, tendrá que defenderse de la misma acusación. Su Dialéctica negativa será interpretada, por algunos constructores de Sistemas, no sólo como una muestra del pensamiento paradojal, sino como un callejón sin salida que impide la acción.

\section{Gadamer, esteta apolítico}

Mostraré algunos de los principales lugares comunes o tópicos de la hermenéutica filosófica tejida por Gadamer, para así determinar su inserción en la lista de pensadores acusados, bien de estetas apolíticos, bien de conservadores.

\section{1. "No podemos trascender el diálogo que somos»}

Estamos ante una de las presuposiciones claves de la hermenéutica filosófica $y$, por tanto, ante una de las tesis sobre las que más se ha polemizado. La imposibilidad de trascender "el diálogo que somos", junto con otros argumentos, permite a Gadamer reivindicar la universalidad de la hermenéutica. En su análisis del lenguaje destaca el valor de una intersubjetividad compartida por los hablantes merced al mundo de la vida. Lo compartido y transmitido lingüísticamente conformaría ese consenso en el que fácticamente hemos crecido. "La filosofía práctica presupone que estamos ya conformados por las ideas normativas en las que fuimos educados y que presiden el orden de toda la vida social [...] El que quiere entender algo trae ya consigo un anticipo de lo que quiere entender, un consenso si quiere persuadir y convencer en las cuestiones debatidas» ${ }^{8}$. Esa anticipa-

${ }^{8}$ H.-G. GADAMER, Verdad y método, Salamanca, Sígueme, 1994 (2." ed.), vol. II, p. 307. La cursiva es mía. 
ción de la comprensión, que trae todo sujeto consigo y que conforma el consenso fáctico, es un punto determinante a la hora de defender la universalidad de la hermenéutica. Más aún, Gadamer mantendrá que la intersubjetividad compartida por los hablantes merced a un mundo de la vida se convierte en la función fundamental del lenguaje. Estaríamos ante la función constituidora del mundo acerca del que se puede hablar'. El lenguaje en esta función nos abre a la verdad al fundar un sentido compartido por los hablantes de una misma tradición. "Esta fundación de sentido se hace por excelencia en el lenguaje de la creación literaria, de lo que los alemanes llaman Dichtung y que es más que la 'poesía' - como se suele traducir - en el sentido de 'lírica' o 'versos'. Es ahí donde crece el ser, o surge la palabra, según distintas fórmulas de Gadamer» ${ }^{10}$. Será, evidentemente, en la literatura y en la retórica donde encontremos los modelos de esta prioritaria función del lenguaje. Con esta función la hermenéutica gadameriana se ontologiza siguiendo a Heidegger. ¿Por qué? Porque convierte la dependencia del diálogo en un inevitable primado de la tradición lingüística.

A partir de aquí entendemos la crítica de Habermas a la hermenéutica filosófica en el capítulo de La lógica de las ciencias sociales que lleva por título "La pretensión de la universalidad de la hermenéutica" (1970 ${ }^{11}$. El francfortiano examina los peligros de acentuar la intersubjetividad ya compartida frente a la generada comunicativamente. El lenguaje natural también es capaz de autorreflexión y más teniendo en cuenta, como dirá Habermas, la posibilidad de que el consenso avalado por la tradición sea también resultado de pseudocomunicaciones, y esté preñado de falsedades. El diálogo que somos, como reconoce A. Wellmer, «es también un plexo de poder y que por eso mismo no es diálogo alguno [...]. La pretensión de universalidad del enfoque hermenéutico sólo puede mantenerse si se parte de que la tradición como lugar de verdad posible y de acuerdo fáctico es también el lugar de la no-verdad fáctica y de la perpetuación del poder” ${ }^{12}$.

9 En el prólogo a la obra de Gadamer Arte y verdad de la palabra (Barcelona, Paidós, 1998), Gerard Vilar expone las diferentes funciones del lenguaje y cómo Gadamer se inclina por la función categorizadora, constituidora o abridora del mundo acerca del que se puede hablar, frente a los que consideran que la función prioritaria sería la cognitiva o la comunicativa.

10 G. VILAR, "Prólogo" de Arte y verdad de la palabra, op. cit., p. 12.

1 J. HaBermaS, La lógica de las ciencias sociales, Madrid, Tecnos, 2002 (3. reimp.), pp. 277306.

${ }^{12}$ Citado en J. Habermas, ibid., p. 301. 
Desde el psicoanálisis y la crítica ideológica (referentes que adopta Habermas), la tesis gadameriana — «no podemos trascender el diálogo que somos»es vista como claramente reaccionaria y conservadora.

\section{2. "No hay oposición entre autoridad y razón»}

De la autocomprensión ontológica de la hermenéutica, que Gadamer desarrolla siguiendo a Heidegger, y que le conduce al inevitable primado de la tradición lingüística, se llega a la rehabilitación del prejuicio.

«Ten el valor de utilizar la autoridad» es una de las máximas que expresa el sentir "contrailustrado" de la hermenéutica filosofica. La autoridad tiene algo que decirnos, algo que no podemos llegar a conocer por nuestra cuenta. En Verdad y método encontramos la respuesta al porqué la hermenéutica gadameriana toma como principio de acción el valor de la autoridad. Gadamer argumentará del siguiente modo: es necesario separar los métodos propios de las ciencias de la naturaleza de los métodos válidos en las ciencias del espíritu; en esta búsqueda de fronteras se encuentra un espacio de la historia humana no trillado por el movimiento de la Ilustración. Los ilustrados apoyan sus métodos en la inteligencia; frente a esto, contemplaremos métodos cercanos a "la memoria, la fantasía, el ritmo, la sensibilidad musical y la experiencia del mundo" ${ }^{13}$. Según el propio Gadamer afirma, esta metodología se halla más cerca de lo que él define como «autoridad» que de la inteligencia que reclamaba el movimiento ilustrado. Ahora bien, ¿qué es autoridad? "Autoridad no es la superioridad de un poder que reclama obediencia ciega y prohíbe pensar. La verdadera esencia de la autoridad reside en no poder ser irracional, en ser un imperativo de la razón, en presuponer en el otro un conocimiento superior que rebasa el juicio propio. Obedecer a la autoridad significa entender que el otro - también la voz que resuena desde la tradición y la autoridad- puede percibir algo mejor que uno mismo» ${ }^{14}$. Leyendo esta caracterización de autoridad podríamos pensar que Gadamer es más kantiano que los propios kantianos. Gadamer define lo que es la autoridad de modo semejante a como Kant define lo que es la Ilustración: razonamiento y obediencia ${ }^{15}$. Al igual que para el filóso-

${ }^{13}$ H.-G. GaDAMER, Verdad y método, vol. II, op. cit., p. 45.

${ }_{14}$ Ibid., p. 45.

${ }^{15}$ Recuérdese que Kant encierra su ensayo ¿Qué es la llustración? con una paradójica respuesta: la Ilustración es tanto razonamiento como obediencia, «razonad, pero obedeced». 
fo prusiano, para Gadamer, dos siglos después, no hay oposición entre razón y autoridad. «La autoridad de la tradición no se impone ciegamente, sino por el reconocimiento reflexivo de aquellos que estando en la tradición la entienden y prosiguen aplicándola ${ }^{16}$. De este modo, la autoridad descansa en el conocimiento y hasta tal punto esto es así que «el que ha alcanzado la mayoría de edad puede, sin estar obligado, asumir por conocimiento lo que había admitido por obediencia " ${ }^{17}$. En definitiva, cuando se habla de autoridad no hay que pensar en un acto de sumisión, un acto irracional, no crítico y de i-libertad, sino que la adhesión a la autoridad ha de ser entendida como un suceso de reconocimiento y conocimiento. La mediación histórica conlleva que nuestro presente se vea interpelado por la tradición. "Lo que satisface a nuestra conciencia histórica es siempre una pluralidad de voces en las cuales resuena el pasado. Este sólo aparece en la multiplicidad de dichas voces: tal es la esencia de la tradición de la que participamos y queremos participar. La moderna investigación histórica tampoco es sólo investigación, sino en parte también mediación de la tradición ${ }^{18}$.

Los críticos de Gadamer, como Habermas, ven que esta identificación de autoridad y razón conduce a una ligazón inevitable entre reconocimiento dogmático y verdadero consenso. Ahora bien, esto sólo sería factible «si en la tradición estuvieran asegurados la ausencia de coacción y el carácter irrestricto del entendimiento intersubjetivo acerca de esa tradición" " ${ }^{19}$. Como este no es el caso, Gadamer estaría reduciendo el momento de ilustración al horizonte de las convicciones vigentes. Se plantea, una vez más, el problema capital de toda filosofía política: ¿es posible un verdadero cambio social? ¿Acaso es posible la revolución si limitamos el momento de emancipación a lo socialmente vigente? ¿Puede darse una revolución sin distanciarnos de una autoridad? ¿'No estaremos, una vez más, ante la creencia fundamental del Príncipe de Salina en El gatopardo tras la revolución garibaldina? ¿Afirmaremos con resignación y regusto aristocrático que todo ha de cambiar para que todo siga igual?... Sin revolución y con la constante referencia gadameriana a la literatura y a la retórica, la acusación de esteta apolítico vuelve a planear sobre Gadamer.

16 J. HABERMAS, La lógica de las ciencias sociales, op. cit., pp. 303-304.

17 H.-G. GaDAMER, Verdad y método, vol. II, p. 236.

18 H.-G. Gadamer, Verdad y método, Salamanca, Sígueme, 1977, vol. I, p. 353.

19 J. HABERMAS, La lógica de las ciencias sociales, op. cit., p. 304. 


\section{3. «El sentido se anticipa pero se corrige constantemente»}

Señalé, en un apartado anterior, como la autocomprensión ontológica de la hermenéutica va unida a una anticipación de sentido que conformaría el consenso en que fácticamente hemos crecido. Esta anterioridad tiene que ver con dos términos claves: círculo hermenéutico y mediación histórica.

Cuando hablamos de círculo hermenéutico, o círculo de la comprensión, estamos ante una regla hermenéutica que facilita conocer cómo iniciar la comprensión. La regla en cuestión recuerda la necesidad de comprender el todo desde lo individual y lo individual desde el todo. A través de esta relación circular nos ayudaríamos a decidir el sentido de un texto. Al fin y al cabo, ante cualquier proceso de comprensión tenemos una expectativa de sentido. Pues bien, "la anticipación de sentido que hace referencia al todo sólo llega a una comprensión explícita a través del hecho de que las partes que se determinan desde el todo determinan a su vez a este todo ${ }^{20}$. No se trata de una anticipación dogmática del sentido de un texto, sino todo lo contrario: las partes mantienen una congruencia con el todo y, al mismo tiempo, el sentido total puede verse modificado por las partes. Si admitiésemos, por el contrario, una anticipación dogmática, ésta podría ser caracterizada como "anticipación de la perfección». Gadamer, intencionadamente, evita este error caracterizando de abierto al círculo de la comprensión: el sentido se anticipa pero se corrige constantemente. Así, por ejemplo, es comprendida la vida, hermenéuticamente, como un círculo abierto entre el todo de la vida y la vivencia parcial. «Toda vivencia está entresacada de la continuidad de la vida y referida al mismo tiempo al todo de ésta [...]. En cuanto que la vivencia queda integrada en el todo de la vida, este todo se hace también presente en ellaw ${ }^{21}$.

En la mediación histórica también se integran dos momentos: la objetividad pasada - transmitida, como hemos visto, como totalidad de sentido- y la subjetividad presente. La dialéctica del comprender ya nos enseñó la apertura del círculo hermenéutico, en el que la mediación histórica es otro botón de muestra de la actividad circular del comprender. «El movimiento de la comprensión va constantemente del todo a la parte y de ésta al todo ${ }^{22}$ o, parafraseando, el movi-

${ }^{20}$ H.-G. GaDAMER, Verdad y método, vol. I., op. cit., p. 360.

${ }^{21}$ Ibid., p. 107.

22 Ibid., p. 361. 
miento de la comprensión oscila entre la subjetividad presente y la objetividad pasada, y entre ésta y la subjetividad presente.

Esta apertura constante, este no cerrarse el círculo, es lo que empuja a diversos intérpretes de la hermenéutica filosófica a caracterizarla como un pensamiento negativo que imposibilita la acción. ¿Es posible la acción política si el círculo de la comprensión no se cierra? Si no damos una respuesta positiva a este interrogante, la acusación de conservadurismo y apoliticismo vuelve a cernirse sobre la filosofía gadameriana.

\section{Gadamer, pensador atribulado}

Los tres tópicos de la hermenéutica filosófica comentados - en el apartado anterior- conducen a ésta a un callejón sin salida. No parece que pueda librarse de los cargos de los que se la acusa: conservadurismo y esteticismo apolítico. Ahora bien, si los lugares comunes que antes he expuesto son interpretados como propios de una tradición de pensamiento atribulado, los cargos podrían desaparecer. Ya hemos visto cómo Kierkegaard es una figura clásica de tal pensamiento, Adorno lo será en el siglo XX. ¿Gadamer ocuparía un lugar en esta lista? Veamos.

\subsection{La imposibilidad de cerrar el círculo}

Gran parte de los pensadores atribulados rechazaron alguna forma de pensamiento especulativo que consideraban dogmático. Kierkegaard ha pasado a la historia como pensador antihegeliano. Su actitud moderna frente a la filosofía - la filosofía, la razón especulativa, ha de ser separada de la fe- es claramente antihegelianizante. Pretender, como hicieron los hegelianos, explicar la fe como una parte más del Sistema es intolerable para el pensador danés. Independientemente de si interpreta bien o mal al filósofo idealista, lo que es evidente es su crítica constante al concepto de sistema. Una cosa es ordenar el pensamiento sistemáticamente -actividad que el mismo Kierkegaard practica-, y otra bien distinta es pretender, como ambiciona Hegel, una algoritmia conceptual que transcriba el mundo: tarea bastante inútil si nos percatamos de que "con la mayoría de los filósofos sistemáticos y sus sistemas ocurre lo mismo que con aquél que luego de construir para sí un castillo, habita en un pajar. Ellos no viven dentro de sus enormes edificios sistemáticos. En el campo del espíritu esto constituye 
una objeción capital. Las ideas de un hombre deben de ser su propia morada; de lo contrario, peor para ellas" ${ }^{23}$. A pesar de estar en contra de la filosofía positiva de los hegelianos, el pensador danés sí ofrece algo. Frente al pensador sistemático, Kierkegaard propone el pensador existencial; frente a las promesas de alcanzar el Espíritu Absoluto, «un pensador existencial produce aquello que anuncia” ${ }^{24}$.

El rechazo de Adorno al concepto de sistema va unido en su propuesta de dialéctica negativa a su crítica al pensamiento identitario. Hauke Brunkhorst entiende por pensamiento identificante la suma y cifra de todos los errores categoriales que se deben a una proyección de categorías lógicas en categorías empíricas. Quienes se introducen en la lógica de lo idéntico se aferran a "una moral sistemática, con axiomas y corolarios, coherencia férrea y aplicación segura a todo dilema moral. [...] Intolerable resulta el intento de sustraerse a la alternativa del 'o esto o lo otro', la desconfianza hacia el principio abstracto, la inflexibilidad sin doctrina” ${ }^{25}$. El pensamiento identitario como una forma de pensamiento dogmático asume que todo avanzar supone una posición de dominio. La razón se manifiesta como poder y dominio. El rechazo de la identidad conlleva la apropiación de una dialécrica negativa que aunque no positiviza, para evitar la cosificación, sí ofrece algo, una teleología: desvelar, aunque parezca paradójico, con los medios del pensamiento conceptual, el maleficio del pensamiento identitario, de la positivización del pensamiento, con el fin último de poder trastocar lo malo existente.

En el caso de Gadamer, su antidogmatismo se manifiesta como un no poder cerrar el ć́rculo de la comprensión. Para explicar el sentido práctico de esta idea acude a una filosofía práctica concreta, la filosofía de Aristóteles. Más aún, interpreta la Ética a Nicómaco como si fuese escrita por un Kierkegaard resucitado: el danés rechaza el dogmatismo de Hegel como el estagirita el de su maestro Platón. Y es que su Ética a Nicómaco "es realmente una crítica a un concepto dogmático de lo bueno en general y a un sistema metafísico en el que desde el punto de vista de Aristóteles lo bueno aparece transmitido en Platón a través de las

${ }^{23}$ S. KIERKEgAaRd, Diario intimo, op. cit., p. 147.

24 Ibid., p. 317.

25 T. AdORNO y M. HORKHEIMER, Dialéctica de la Ilustración, Madrid, Trotta, 1994, p. 283. 
matemáticas y la cosmología, que es lo mismo que según Kierkegaard ocurrió en el pensamiento de Hegel ${ }^{26}$.

La filosofía práctica válida en una hermenéutica filosófica que anticipa el sentido, al mismo tiempo que lo corrige constantemente, no puede consistir en la aplicación de principios abstractos y formales; una «auténtica» filosofía práctica surge de la experiencia de la práctica misma (consenso en el que fácticamente hemos crecido) "gracias a lo que en ella hay de razón y de razonable" ${ }^{27}$. Si Gadamer permaneciera dentro de esta caracterización, sí mantendría un tipo de pensamiento conservador. Pero, precisamente, el que el círculo no se cierre quiere decir que no podemos permanecer anclados en lo vigente socialmente, en la tradición, ni rechazar el cambio revolucionario. Como dice Gadamer respondiendo a sus críticos: «Nada justifica la suposición de que yo aprobaría el 'consenso básico' con una parte más que con la otra, como solidaridad conservadora y no como solidaridad revolucionaria ${ }^{28}$. El que el círculo no se cierre no significa que no podamos actuar políticamente. Gadamer también hace su propuesta: aprender a reconocer en lo otro y lo diferente lo común, en esto consiste la apertura del círculo hermenéutico ${ }^{29}$. Gadamer, en ocasiones, se ayuda del término kierkegaardiano «simultaneidad" para explicar la mediación y el abrirse. «En Kierkegaard 'simultáneo' no quiere decir 'ser al mismo tiempo', sino que formula la tarea planteada al creyente de mediar lo que no es al mismo tiempo, el propio presente y la acción redentora de Cristo, de una manera tan completa que esta última se experimente a pesar de todo como algo actual (y no en la distancia del entonces), y que se la tome en serio como tal ${ }^{30}$. Tanto la mediación histórica como la apertura exigen simultaneidad. La primera, ya lo hemos visto, se manifiesta como mediación entre la objetividad pasada y la subjetividad presente; la segunda, la apertura, reclama simultaneidad en el sentido de que "algo único que se nos representa, por lejano que sea su origen, gana en su representación una plena presencian. Esta es la llamada a lo otro, a lo diferente, que propone Gadamer y que se complementa con su rechazo a la adaptación. Kierkegaard y Ador-

${ }^{26}$ H.-G. GADAMER, El giro hermenéutico, Madrid, Cátedra, 1998, p. 214.

${ }^{27}$ Ibid., p. 183.

${ }^{28}$ H.-G. GADAMER, Verdad y método, vol. Il., op. cit., p. 260.

${ }^{29}$ Véase H.-G. GADAMER, "Ciudadano de dos mundos", en El giro hermenéutico, Madrid, Cátedra, 1998, pp. 173-186.

${ }^{30}$ H.-G. GADAMER, Verdad y método, vol. I., op. cit., p. 173. 
no también fueron dos críticos atroces de la adaptación. El que se adapta sí es el conservador. A pesar del espíritu de autoconservación que se vive desde la modernidad, todavía podemos esperar algo diferente: «Es posible que vivamos en un mundo en el que predomina el adaptarse, la reglamentación y la valoración excesiva de toda capacidad de adaptación. Sin embargo, siempre intentaremos defendernos de esta excesiva presión para que nos adaptemos. Es en esto donde también se encuentra la posibilidad de que nos comuniquemos los unos con los otros" ${ }^{31}$. En definitiva, ahí es donde reside la apertura y la posibilidad de cambio, de acción social.

\subsection{La no oposición entre autoridad y razón}

La única forma de evitar que esta tesis de la hermenéutica filosófica conduzca, inevitablemente, a la ligazón del reconocimiento dogmático con el verdadero consenso es entendiendo la relación entre autoridad y razón a través de un concepto adorniano: el concepto «constelación». Tal término es una metáfora que Adorno tomó prestada de Benjamin. Con él designa «un conjunto yuxtapuesto, más que integrado, de elementos cambiantes que se resisten a ser reducidos a un común denominador, a un núcleo central o a un primer origen generador ${ }^{32}$. Con la utilización de este término se evitaría la reducción de todo momento revolucionario a la autoridad, a lo socialmente vigente. La constelación eludiría tanto la unidad indiferenciada entre autoridad y razón como su hostilidad antitética. Si no evitamos la unidad indiferenciada caemos en la tiranía de lo vigente socialmente, si no evitamos las posiciones antagónicas desvirtuamos el sentido de la mediación histórica, de la dialéctica. Al hablar de constelación entre autoridad y razón apelamos a una comunicación de lo que se halla diferenciado. Sólo interpretando en este sentido la tesis gadameriana evitaremos la acusación de conservadurismo y de esteticismo apolítico.

\subsection{Forma de vida y actitud política}

Gadamer, al igual que Adorno e incluso que Kierkegaard, es un pensador preocupado no por una ética formal, sino por una ética de la vida buena. De

${ }^{31}$ H.-G. GADAMER, El giro hermenéutico, op. cit., p. 238.

${ }^{32}$ M. JAY, Adorno, Madrid, Siglo XXI, 1988, p. 5. 
igual modo que no hace una teoría moral formal tampoco elabora una teoría política de tales características.

¿Se le puede acusar, al igual que algunos acusaron a Adorno, de ser, por ello, un esteta apolítico? No lo creo. Hacer hincapié en una forma de vida, a la manera aristotélica, es ya hacer política. Todas sus reflexiones sobre la vida buena le conducen a la política. Más concretamente: Gadamer se detiene en una manera clásica de hacer política, relacionada con la ciudad y la ciudadanía. A la manera aristotélica planifica su modelo de filosofía práctica, de ética y de política: «Para el método de filosofía práctica esto significa que se debe partir de los 'legómena' - los 'dóxaì generales sobre lo bueno, el eudemonismo y los 'aretai — [...] Sólo quien ocupa un lugar 'en la sociedad', es decir, en la polis, es capaz de darse cuenta de lo insostenible de argumentaciones extrañas al objeto [...]. Quien como ciudadano de una ciudad no haya desarrollado un buen sentido político, ese no puede aplicar razonablemente el saber de lo general, por ejemplo el ideal de una constitución estatal o una amplia recopilación de formas políticas constitucionales " ${ }^{33}$. Como el propio Gadamer reconoce, para la teoría científica moderna su tipo de reflexión política parece insuficiente. Ahora bien, «ni la retórica ni la hermenéutica en cuanto formas concretas de vida son independientes de lo que Habermas llama la anticipación de la vida justa. Esta anticipación subyace en toda participación social y en sus esfuerzos por alcanzar un consenso [...]. También la anticipación de la vida justa, que es esencial para toda razón práctica, debe concretarse, es decir, debe asumir en su conciencia el neto contraste entre los meros deseos y los auténticos objetivos de la voluntad activa. Creo que mi tema se puede identificar con un viejo problema que ya Aristóteles tiene presente [...] El bien humano es algo que encontramos en la praxis humana y es indefinible sin la situación concreta en la que se prefiere una cosa a otra ${ }^{34}$.

Ni Aristóteles ni Gadamer se despreocupan del planteamiento político. Incluso, al igual que el primero, Gadamer podría ser interpretado como defensor de alguna forma de republicanismo. Pero esto es ya tema de otro artículo.

33 H.-G. GADAMER, El giro hermenéutico, op. cit., pp. 190-191.

34 H.-G. GADAMER, Verdad y método, vol. II., op. cit., p. 264. 